\title{
Biodentine Pulpotomy as a Treatment Modality for Tooth with Chronic Hyperplastic Pulpitis - A Case Report
}

\author{
Pragati Sachan ${ }^{1}$, Neelam Mittal ${ }^{2}$ \\ ${ }^{1}$ Department of Conservative Dentistry \& Endodontics, AIIMS, Bhubaneswar, Odisha, India, ${ }^{2}$ Conseravative Dentistry \& Endodontics, \\ Faculty of Dental Sciences, IMS, BHU, Varanasi, Uttar Pradesh, India
}

Email for correspondence: sachan.pragati@gmail.com

\begin{abstract}
Chronic hyperplastic pulpitis, which is also known as pulp polyp, occurs as a reparative response of pulp tissue in the presence of chronic pulpitis. Proliferative nature of diseased pulp indicates its favorable reparative potential. Nowadays, biodentine pulpotomy is emerging as an alternative to root canal treatment in cases of irreversible pulpitis in some selected cases. The present case report describes successful management of tooth affected with chronic hyperplastic pulpitis with biodentine pulpotomy. Patient was completely asymptomatic, and the tooth was free of any clinical and radiographic signs of inflammation and infection at follow-up visits after 3 and 6 months.
\end{abstract}

Key words: Biodentine, chronic hyperplastic pulpitis, pulpotomy, root canal treatment

\section{INTRODUCTION}

The term chronic hyperplastic pulpitis is attributed to the development of granulation tissue, most of the times covered with epithelium and resulting from long-standing, low-grade irritation. ${ }^{[1]}$ Pulp polyp is more common in teeth of children and adolescents, in which the pulp tissue has a high resistance and a good blood supply. Its color may vary from cherry red of the granulation tissue to opaque whiteness of moist keratinized epithelium, depending on the degree to which the appearance of the granulation tissue is modified by its covering. It is usually symptomless, but discomfort can occur during mastication by the pressure caused due to the food bolus. Response to thermal and electrical stimuli may be normal and it might mimic the proliferating gingival tissues. ${ }^{[2,3]}$ The purpose of the present case report is to describe the conservative

\begin{tabular}{|l|l|}
\hline Quick Response Code & Article Info: \\
\hline doi: 10.5866/2017.9.10242 \\
\hline $\begin{array}{l}\text { Received: } 11-12-2017 \\
\text { Revised: } 22-12-2017 \\
\text { Accepted: 19-01-2018 } \\
\text { Available Online: 15-02-2018, 2018 (www. } \\
\text { nacd.in)@ NAD, 2018 - All rights reserved }\end{array}$ \\
\hline
\end{tabular}

management of hyperplastic pulpitis in left maxillary molar in young-aged patient.

\section{CASE REPORT}

A 14-year-old female reported to our department with chief complaint of decayed upper left back tooth. Intraoral examination revealed a large polypoid lesion about $10 \mathrm{~mm} \times 5 \mathrm{~mm}$ wide with a $2 \mathrm{~mm}$ diameter stalk protruding from the carious cavity of tooth 26 . Tooth was non-tender to percussion and responds normally to thermal and electrical pulp testing. Pulpal growth was pale pink in color and was covering the carious cavity in relation to tooth 26 [Figure 1]. Radiographic examination revealed radiolucency extending till the pulp chamber of tooth 26 [Figure 2]. On the basis of clinical and radiographic examination, diagnosis of chronic hyperplastic pulpitis with respect to tooth 26 was made.

Tooth was anesthetized and isolated with rubber dam. Initially, cavity outline preparation was undertaken using a high-speed turbine under copious water spray. All unsupported enamel and carious dentin were removed using conventional burs and a sharp spoon excavator. After washing the prepared cavities with sterile saline solution, the polyp was excised with sterile excavator [Figure 3]. Hemorrhage was controlled using saline solution 
and sterile cotton pellets with high pressure. After that, freshly mixed Biodentine ${ }^{\mathrm{TM}}$ (Rue du Pont de Créteil, 94100 Saint-Maur-des-Fossés, France) was immediately placed over the exposed pulp, following which it was allowed to set for 20 min [Figure 4]

The exposed dentin and biodentine were both sealed with GIC. After setting of GIC, surface was etched, rinsed with water and blot dried. Next, the bonding agent (Prime and Bond NT- Dentsply Caulk, Milford, DE) was applied to the tooth and cured. Finally, tooth was restored with composite resin and light cured [Figure 5]. Periodic follow-ups were carried out in which tooth was asymptomatic [Figure 6].

\section{DISCUSSION}

Pulp polyp occurs as a result of an open and large cavitated carious lesion which performs as a

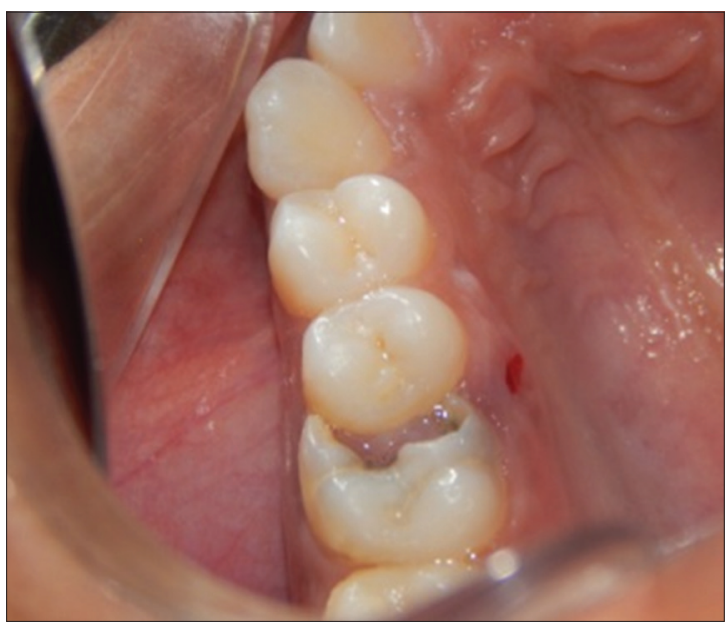

Figure 1: Pre-operative clinical view showing pulpal growth covering the carious cavity in relation to tooth 26

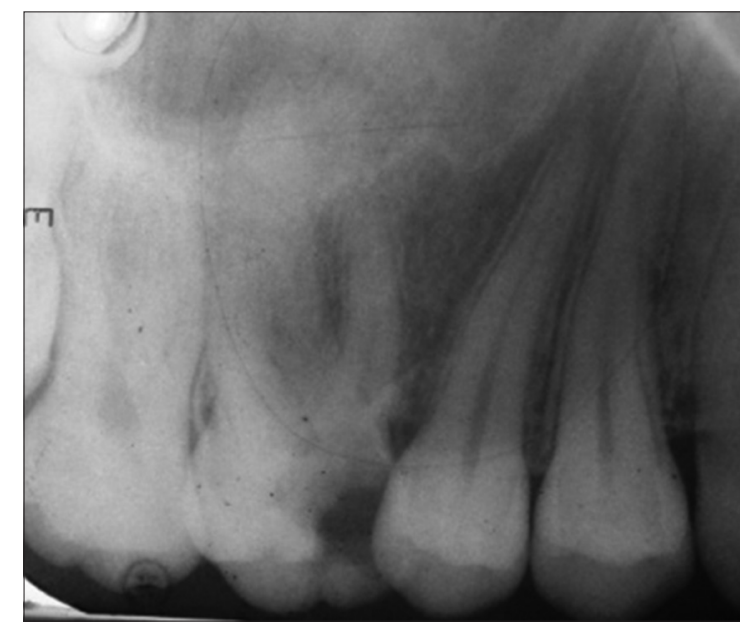

Figure 2: Pre-operative radiograph showing radiolucency extending till the pulp chamber of tooth 26

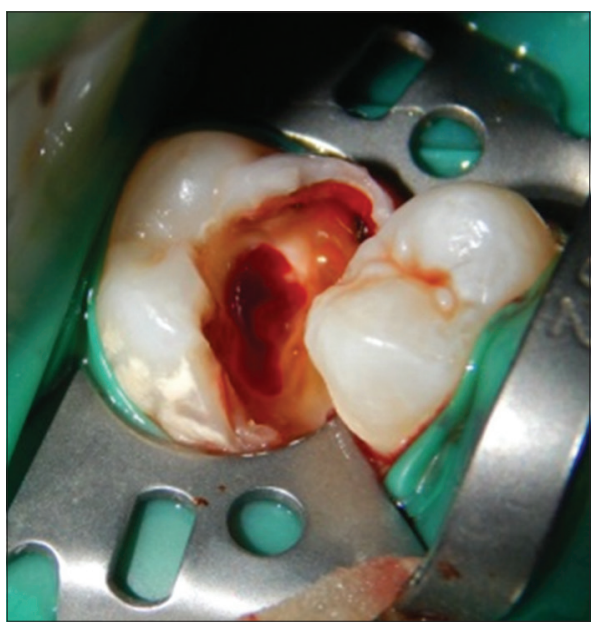

Figure 3: Clinical picture showing excision of the pulp polyp with sterile excavator

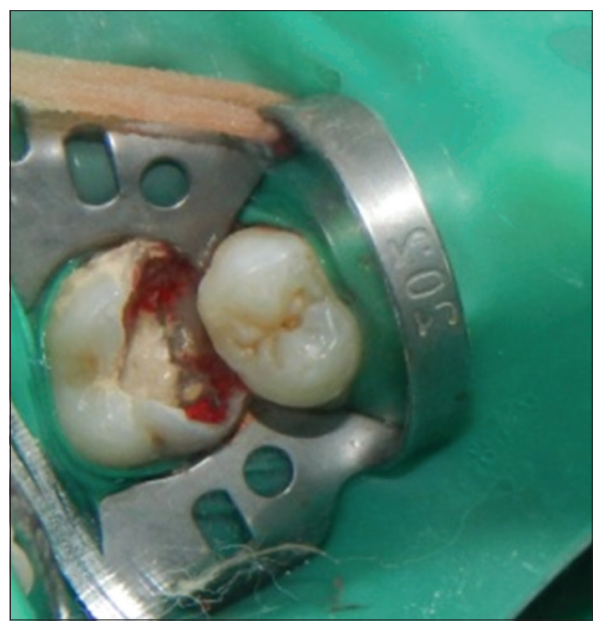

Figure 4: Clinical picture showing placement of biodentine

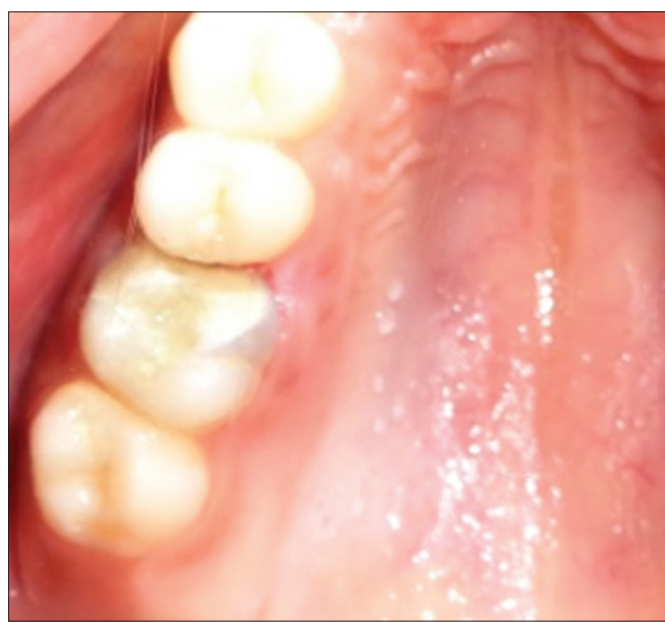

Figure 5: Post-operative clinical view of showing completely restored 26 with composite 


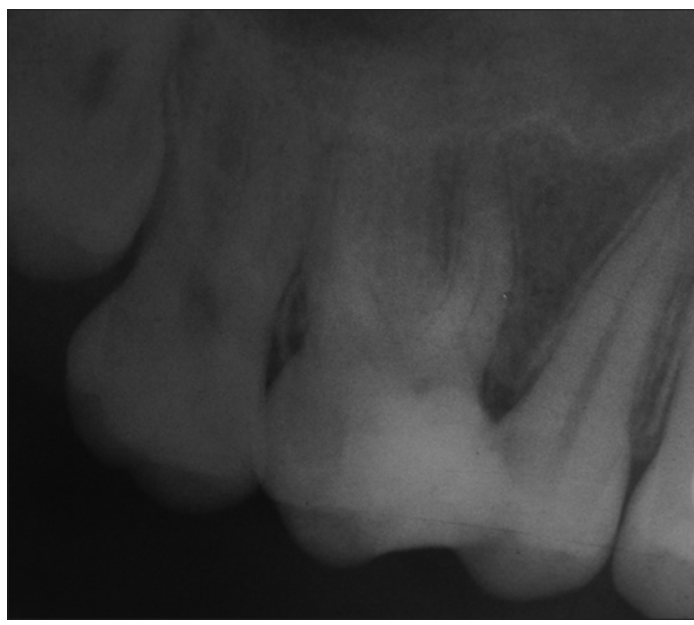

Figure 5: Post-operative clinical view of showing completely restored 26 with composite

pathway for escape of the inflammatory exudate, tooth fracture due to trauma with pulpal exposure and even long-standing fractured restoration can lead to pulpal stimuli and result in pulpal reactions causing pulp polyp. Type I hypersensitivity reactions are also been hypothesized to play a role in pathogenesis of pulp polyp due to the higher concentration of histamine, immunoglobulin $\mathrm{E}$, and interleukin-4. ${ }^{[4]}$

When pulp involvement is extensive or long standing, periapical radiograph may reveal an incipient chronic apical periodontitis. ${ }^{[5]}$ Stabholz et al. and Caliskan reported that hyperplastic pulpitis associated with periapical involvement presented as radiolucencies or radiopacities on radiographic examination. ${ }^{[6-8]}$ Histopathologically, the surface of polyp usually shows epithelization or even full keratinization. The tissue in the pulp chamber is often transformed into granulation tissue, which projects from the pulp into the carious lesion. There may be fibrosis and calcific degeneration in some area of coronal pulp. It has been reported histologically that radicular pulp tissue may be normal and vital or it may show only a minimal chronic inflammatory reaction in hyperplastic pulpitis.

Root canal therapy or even extraction is recommended for the teeth with hyperplastic pulpitis as damage to the crown is of such an extent that it cannot be restored. In cases of young adults with hyperplastic pulpitis, where there is only coronal pulpal tissue involvement pulpotomy has also been suggested as a treatment option. ${ }^{[1]}$ In the present case report, biodentine pulpotomy was selected as best treatment option as it is conservative and the patient was young with the non-tender tooth as well as responded normally to thermal and electrical pulp testing.

Biodentine (Septodont, Saint Maur des Fosses, France) was used for the pulp capping procedures because of its good sealing ability, short setting time, biocompatibility, bioactivity, and biomineralization properties and was a better option than MTA for a single sitting pulpotomy procedure. ${ }^{[9]}$

\section{CONCLUSION}

On the basis of favorable outcome of abovementioned case, biodentine pulpotomy can be stated as a promising alternative treatment modality for the tooth with chronic hyperplastic pulpitis. However, appropriate case selection such as age of patient, restorability of crown, and inflammatory status of pulp remain important criteria to get the successful outcome.

\section{REFERENCES}

1. Grossman LI, Oliet S, Del Rio CE. Endodontic Practice. $11^{\text {th }}$ ed. Philadelphia, USA: Lea \& Febiger; 1988. p. 105.

2. Spouge JO. Oral Pathology. St. Louis: CV Mosby; 1973. p. $57-61$.

3. Walton RE, Pashley DH, Dowden WE. Pulp pathosis. In: Ingle JI, Taintor FC, editors Endodontics. $3^{\text {rd }}$ ed. Philadelphia, USA: Lea \& Febiger; 1995. p. 398-402.

4. Sattari M, Haghighi AK, Tamijani HD. The relationship of pulp polyp with the presence and concentration of immunoglobulin $\mathrm{E}$, histamine, interleukin 4 and interleukin 12. Aust Endod J 2009;35:1648.

5. Smulson MH, Sieraski SM. Histophysiology and diseases of in dental pulp. In: Weine FS, editor. Endodontic Therapy. $4^{\text {th }}$ ed. St. Louis, USA: CV Mosby; 1989. p. 142-5.

6. Stabholz A, Shekter M, Schwartz Z. Condensing osteitis and chronic hyperplastic pulpitis in the same pulpally involved tooth. Quint Int 1982;2:137-8.

7. Çalı kan MK. Success of pulpotomy in the management of hyperplastic pulpitis. Int Endod J 1993;26:142-8.

8. Çalı kan MK. Pulpotomy of carious vital teeth with periapical involvement. Int Endod J 1995;28:172-6.

9. Koubi G, Colon P, Franquin JC, Hartmann A, Richard G, Faure MO, et al. Clinical evaluation of the performance and safety of a new dentine substitute, Biodentine, in the restoration of posterior teeth - a prospective study. Clin Oral Investig 2013;17:243-9. 